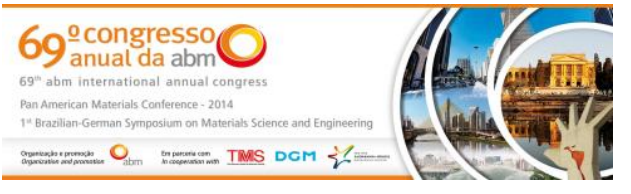

Tema: Diagramas de fases e Transformação de fases

\title{
INFLUÊNCIA DO TEMPO E DA TEMPERATURA DE SOLUBILIZAÇÃO NO TAMANHO DE GRÃO AUSTENÍTICO E FERRÍTICO, E NA FRAÇÃO DE FERRITA DE UM AÇO INOXIDÁVEL DÚPLEX UNS S31803*
}

Rafael Malagutti Leandro ${ }^{1}$ Rodrigo Magnabosco ${ }^{2}$

\begin{abstract}
Resumo
O objetivo deste trabalho é avaliar a influência do tempo e temperatura de tratamento térmico de solubilização no tamanho de grão e na fração de ferrita de um aço inoxidável dúplex UNS S31803 (SAF 2205). A chapa do aço em estudo foi laminada com $22 \%$ de redução de espessura antes de ser solubilizada a $1.000^{\circ} \mathrm{C}, 1.100^{\circ} \mathrm{C}$ e $1.200^{\circ} \mathrm{C}$, por tempos de até $96 \mathrm{~h}$. A fração de ferrita das amostras foi obtida por medidas magnéticas em ferritoscópio e por estereologia quantitativa. Já o tamanho de grão foi determinado por estereologia quantitativa de imagens obtidas por microscopia óptica. Observou-se o aumento da fração de ferrita em função da temperatura de tratamento, como esperado, e foi realizado comparativo entre as duas técnicas de determinação da fração de ferrita com simulações de equilíbrio em Thermo-Calc $\circledast$. O intercepto médio das amostras solubilizadas a $1.000^{\circ} \mathrm{C}$ manteve-se praticamente constante em todos os tempos de solubilização estudados, em aproximadamente 9 micrômetros; após $5 \mathrm{~h}$ de solubilização a $1.100^{\circ} \mathrm{C}$, e após $30 \mathrm{~min}$ a $1.200^{\circ} \mathrm{C}$, contudo, observou-se significativo crescimento de grão nas amostras.
\end{abstract}

Palavras-chave: Aços inoxidáveis dúplex; Tamanho de grão; Fração de ferrita; Transformação de fases; Quantificação de fases.

\section{INFLUENCE OF TIME AND TEMPERATURE OF SOLUTION HEAT TREATMENT ON AUSTENITIC AND FERRITIC GRAIN SIZE, AND ON FERRITE CONTENT OF A DUPLEX STAINLESS STEEL UNS S31803 (SAF 2205)}

\section{Abstract}

The objective of this work is to study the influence of time and temperature of solution heat treatment on grain size and ferrite content of a duplex stainless steel UNS S31803 (SAF 2205). The steel sheet under study was cold rolled with $22 \%$ reduction in thickness before being annealed at $1,000^{\circ} \mathrm{C}, 1,100^{\circ} \mathrm{C}$ and $1,200^{\circ} \mathrm{C}$ for times up to $96 \mathrm{~h}$. The ferrite content of samples was obtained by magnetic measurements with feritscope and quantitative stereology. Grain size was determined by quantitative stereology over images obtained by light microscopy. It was observed the increase of the ferrite content with the increase of treatment temperature, as expected, and a comparison of the values of ferrite content obtained by the two techniques with equilibrium simulations by Thermo-Calc $\AA$ was performed. The average intercept of solution-treated samples at $1,000^{\circ} \mathrm{C}$ remained practically constant for all times studied, at approximately 9 micrometers; after $5 \mathrm{~h}$ at $1,100^{\circ} \mathrm{C}$ and after $30 \mathrm{~min}$ at $1,200^{\circ} \mathrm{C}$, however, there was a significant grain growth in the samples

Keywords: Duplex stainless steels; Grain size; Ferrite content; Phase transformation; Phase quantification.

1 Engenheiro de Materiais, Centro Universitário da FEI, São Paulo, SP, Brasil.

2 Engenheiro Metalurgista, Prof. Dr. do Departamento de Engenharia de Materiais do Centro Universitário da FEI, São Bernardo do Campo, SP, Brasil.

\footnotetext{
* Contribuição técnica ao 69 Congresso Anual da ABM - Internacional e ao 14ํㅡㄹ ENEMET - Encontro Nacional de Estudantes de Engenharia Metalúrgica, de Materiais e de Minas, 21 a 25 de julho de 2014, São Paulo, SP, Brasil.
} 


\section{INTRODUÇÃO}

O estudo de caracterização de aços é muito importante para o desenvolvimento de novas tecnologias, o que acarreta numa melhoria na qualidade de produtos que são fabricados para as mais diversas áreas onde esse material é utilizado. Os aços inoxidáveis dúplex não são materiais novos, existindo relatos de que foram descobertos em meados da década de 30 nos Unieux Laboratories, do Jacob Holzer Group. A primeira aplicação foi principalmente como ligas para fundição, nos anos 30 e 40, na Suécia, Alemanha e França [1]. A família dúplex, como o próprio nome sugere, é composta por ligas que contém essencialmente duas fases, austenita e ferrita, que em frações aproximadamente iguais geram excelente combinação de resistência à corrosão, resistência mecânica, à abrasão e facilidade de processamento, se comparadas a outras ligas. Essas propriedades atendem as necessidades de indústrias químicas, petroquímicas, de papel e celulose, de agroquímicos, marítima, de óleo e gás, entre outras, o que torna o dúplex apropriado para essas utilizações.

O objetivo deste trabalho é fazer um estudo da influência das variáveis tempo e temperatura de um tratamento térmico de solubilização no tamanho de grão austenítico e ferrítico, e na fração de ferrita de um aço inoxidável dúplex UNS S31803. Espera-se, que através desse estudo, seja possível identificar as melhores condições de processamento desse material.

Os aços inoxidáveis dúplex são ligas que apresentam o sistema ferro-cromo-níquel como composição química principal, e possuem microestrutura composta essencialmente por ferrita e austenita. Por apresentarem essa combinação de fases, se comparados aos ferríticos, possuem melhor plasticidade, soldabilidade e tenacidade, e, se quando comparados aos austeníticos, possuem maior resistência mecânica e melhor resistência à corrosão de maneira geral [2]. Além disso, características específicas que distinguem os aços dúplex das outras famílias de aços inoxidáveis são a habilidade de incorporar altas concentrações de cromo e molibdênio (elementos químicos que controlam a resistência do aço à corrosão galvânica e por pite), a boa resistência à corrosão sob tensão fraturante causada pelo cloro, e a alta resistência mecânica à temperatura ambiente.

Os produtos que podem ser produzidos a partir desse aço, por justamente apresentar as propriedades destacadas anteriormente, são trocadores de calor, centrifugadores, bombas, válvulas, tubos e estruturas em geral [3].

Abordando especificamente 0 aço dúplex, interfaces entre austenita e ferrita são bloqueios ao deslocamento das discordâncias na rede cristalina e geram aumento de resistência [4]. As propriedades mecânicas típicas do aço SAF 2205 são 770 MPa de limite de resistência, $515 \mathrm{MPa}$ de limite de escoamento e alongamento de $32 \%(50 \mathrm{~mm})$. A excelente resistência mecânica exibida se deve pela presença de nitrogênio como solução sólida intersticial na austenita e pelo reduzido tamanho de grão típico desse aço [5].

Os aços inoxidáveis dúplex apresentam excelente resistência à corrosão generalizada e por pite. $O$ reduzido teor de carbono comumente encontrado nesse tipo de aço diminui sua susceptibilidade à sensitização, e o permite desenvolver grande resistência à corrosão intergranular [6]. Os altos teores de cromo, níquel, molibdênio e nitrogênio são os responsáveis pela boa resistência à corrosão exibida pelo aço dúplex. A ótima resistência à corrosão e a propriedade de resistência à corrosão sob tensão aplicada são resultado da microestrutura composta pelas estrutura dúplex, dada pela combinação de propriedades de ferrita e austenita [7].

\footnotetext{
* Contribuição técnica ao $69^{\circ}$ Congresso Anual da ABM - Internacional e ao 14ํㅡㄹ ENEMET - Encontro Nacional de Estudantes de Engenharia Metalúrgica, de Materiais e de Minas, 21 a 25 de julho de 2014, São Paulo, SP, Brasil.
} 


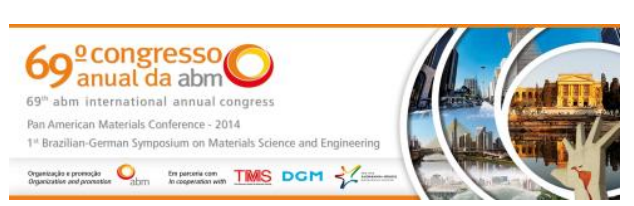

Além da esteorologia quantitativa, a fração de ferrita foi medida pelo equipamento ferritoscópio Fischer MP30. Fez-se 50 medições ao longo das seções longitudinais das 18 amostras tratadas, e calculou-se a quantidade média de fase ferrita em cada uma, bem como o desvio padrão. Usando-se o software Thermo-Calc, a base de dados TCF6 e a composição química da Tabela 1, calculou-se a fração de ferrita de equilíbrio nas três temperaturas estudadas, para comparação destes valores com as medidas experimentais descritas.

\section{RESULTADOS E DISCUSSÃO}

Serão apresentados e discutidos os dados (micrografias e gráficos) obtidos para análise do tamanho de grão e da fração de ferrita nas três diferentes condições de solubilização, e antes da solubilização.

Ao ter o foco sobre as microestruturas solubilizadas a $1000^{\circ} \mathrm{C}$, pode-se fazer um comparativo entre a microestrutura da amostra encruada (deformada plasticamente com $22 \%$ de redução de espessura) e a amostra solubilizada a $1000^{\circ} \mathrm{C}$ por 10 minutos. Observa-se pelas micrografias apresentadas na Figura 1a que a amostra solubilizada, com a menor temperatura e o menor tempo dentre os estudados, sofreu os fenômenos de recuperação e recristalização, fato evidenciado pela reorganização da microestrutura da Figura $1 b$.

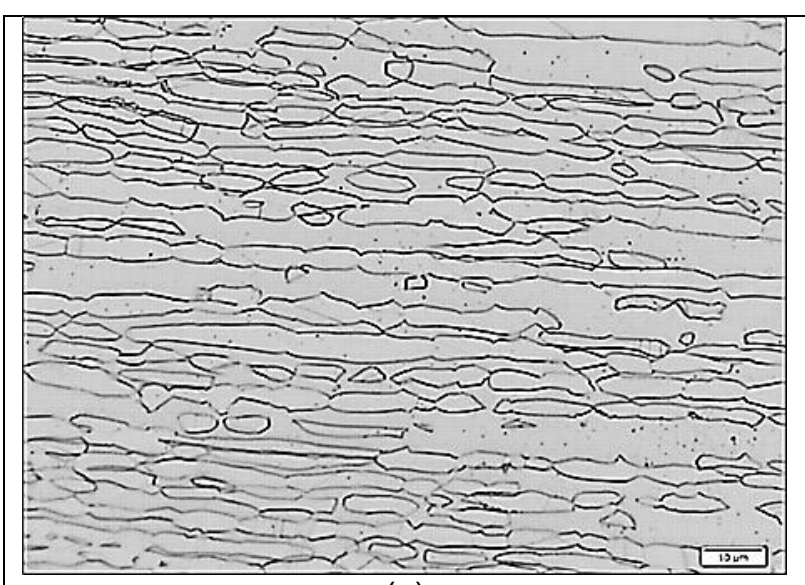

(a)

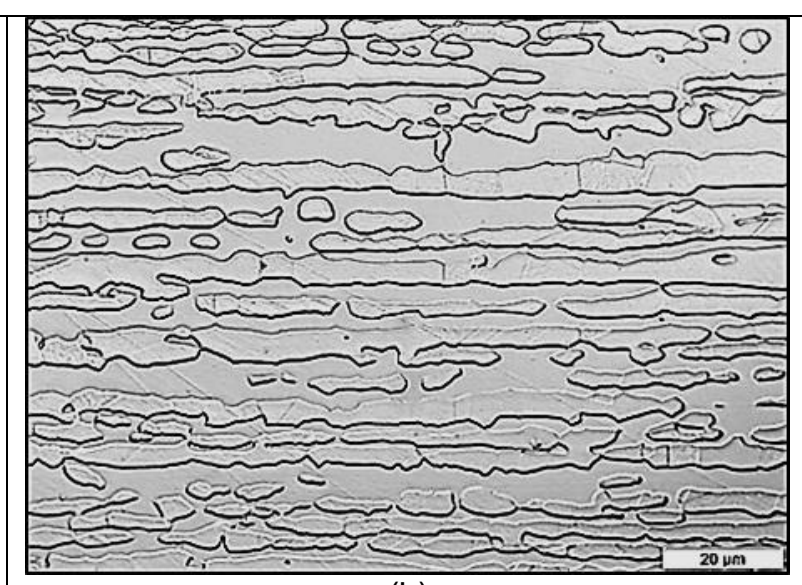

(b)

Figura 1: (a) Microestrutura da amostra deformada plasticamente; (b) Microestrutura da amostra solubilizada a $1000^{\circ} \mathrm{C}$ por $10 \mathrm{~min}$. Aumento: 1000x. Ataque: Oxálico.

Na Figura 2, são comparadas as microestruturas das amostras tratadas pelo menor e maior tempo a $1000^{\circ} \mathrm{C}$. É possível observar que as microestruturas da Figura 2 são bem organizadas, do ponto de vista de distribuição das duas fases (austenita e ferrita).

\footnotetext{
* Contribuição técnica ao $69^{\circ}$ Congresso Anual da ABM - Internacional e ao 14ํㅡㄹ ENEMET - Encontro Nacional de Estudantes de Engenharia Metalúrgica, de Materiais e de Minas, 21 a 25 de julho de 2014, São Paulo, SP, Brasil.
} 


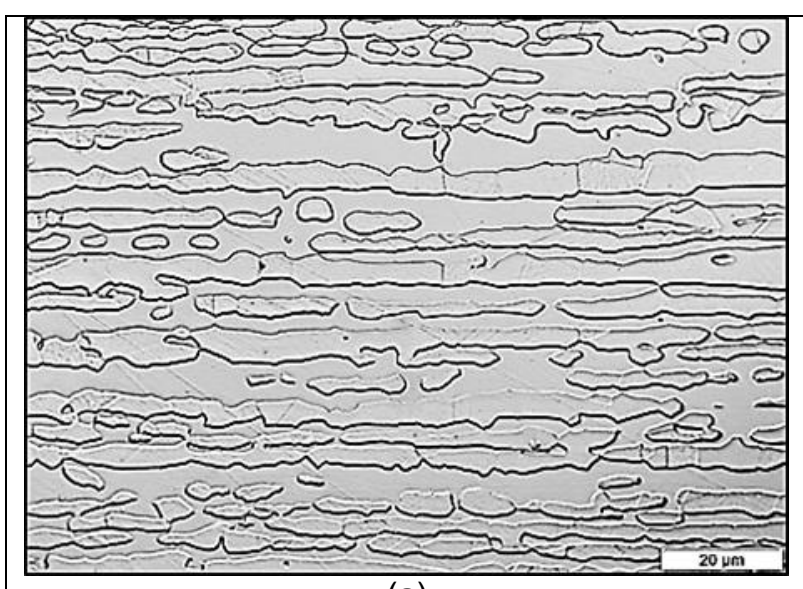

(a)

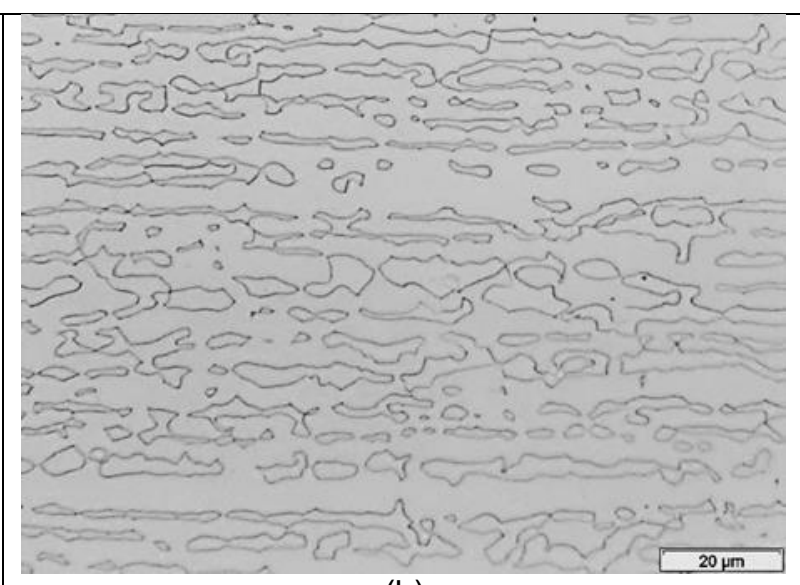

(b)

Figura 2: a) Amostra solubilizada a $1000^{\circ} \mathrm{C}$ por $10 \mathrm{~min}$; b) Amostra solubilizada a $1000^{\circ} \mathrm{C}$ por 96 horas.

O estudo das amostras solubilizadas a $1100^{\circ} \mathrm{C}$ está descrito a seguir. Com o intuito de fazer uma melhor análise da microestrutura, são colocadas lado a lado na Figura 3, as microestruturas de menor e maior tempo de tratamento, objetivando verificar as transformações ocorridas. Nota-se uma grande diferença no tamanho de grão entre as duas condições, já que se identifica um tamanho de grão muito maior da amostra tratada a 96 horas (Figura 3b) em relação à tratada por 10 minutos (Figura 3a).

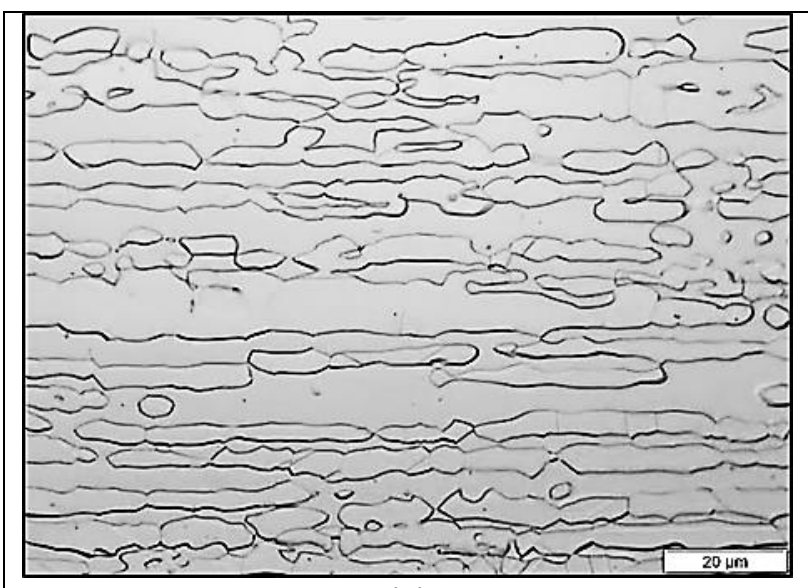

(a)

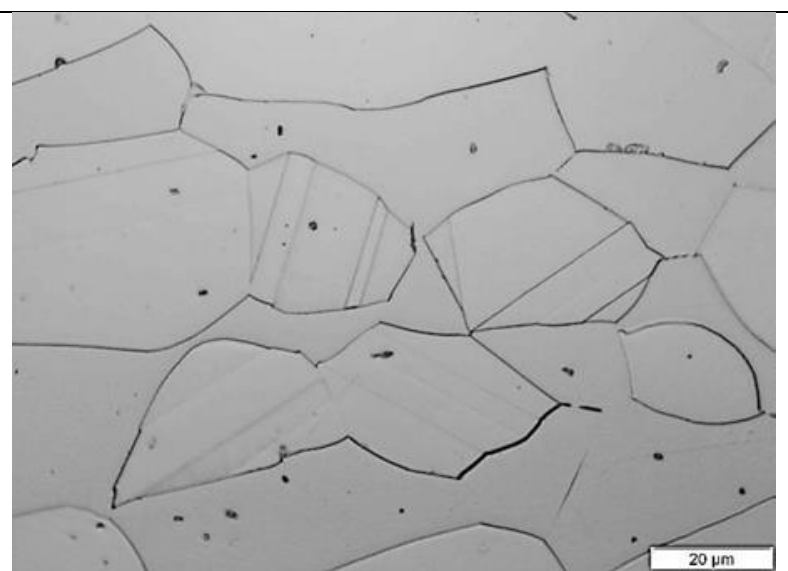

(b)

Figura 3: Amostra tratada a $1100^{\circ} \mathrm{C}$ por $10 \mathrm{~min}$; b) Amostra tratada a $1100^{\circ} \mathrm{C}$ por $96 \mathrm{~h}$. Aumento: 1000x.

São colocadas em destaque na Figura 4 as micrografias das amostras tratadas a 10 minutos e a 96 horas, para melhor avaliação do efeito gerado pelo aumento do tempo de tratamento. Através das micrografias da Figura 4, pode-se observar 0 crescimento excessivo dos grãos presentes na microestrutura da amostra tratada a $1200^{\circ} \mathrm{C}$ por um tempo de 96 horas em relação ao tamanho de grão da amostra tratada a 10 minutos.

\footnotetext{
* Contribuição técnica ao $69^{\circ}$ Congresso Anual da ABM - Internacional e ao 14ํㅡㄹ ENEMET - Encontro Nacional de Estudantes de Engenharia Metalúrgica, de Materiais e de Minas, 21 a 25 de julho de 2014, São Paulo, SP, Brasil.
} 


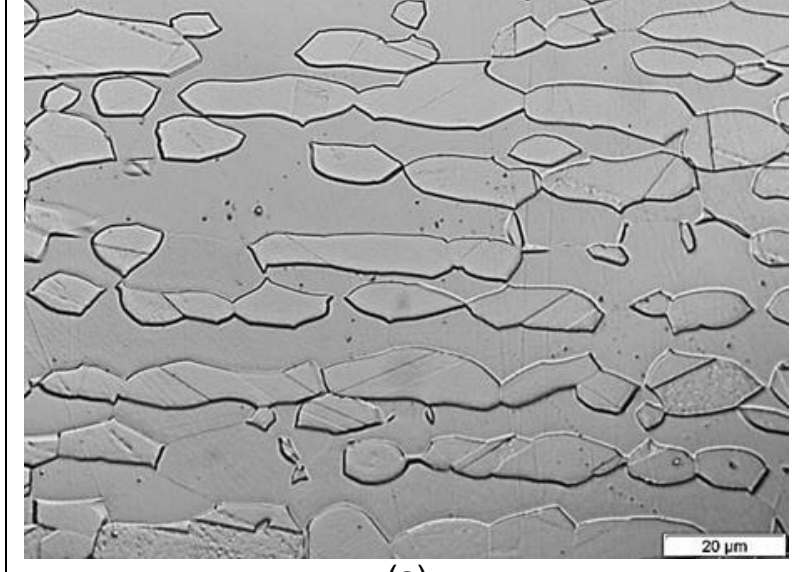

(a)

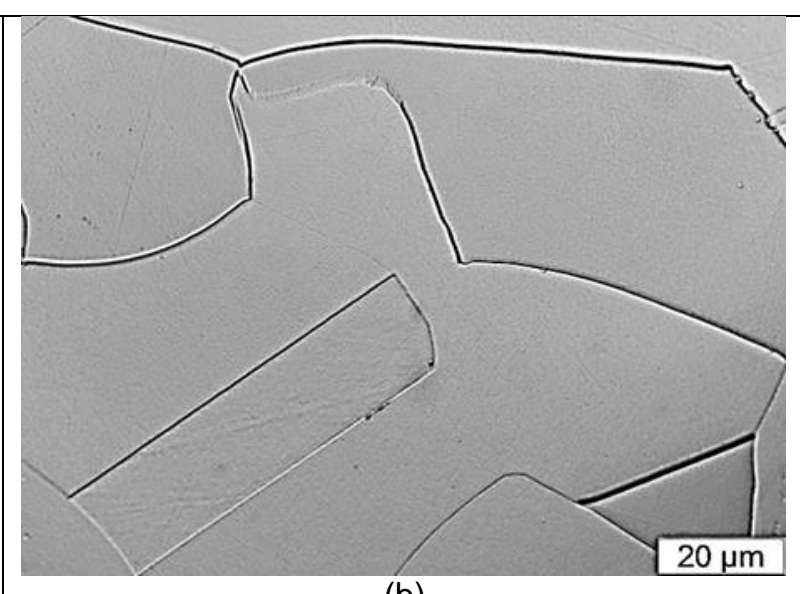

(b)

Figura 4: a) Amostra tratada a $1200^{\circ} \mathrm{C}$ por $10 \mathrm{~min}$; b) Amostra tratada a $1200^{\circ} \mathrm{C}$ por $96 \mathrm{~h}$. Aumento: 1000x.

Além das microestruturas das Figuras 2 a 4, construiu-se um gráfico comparando os comportamentos quanto ao crescimento de grão das fases ferrita e austenita nas três temperaturas de solubilização estudadas, que pode ser visto na Figura 5.

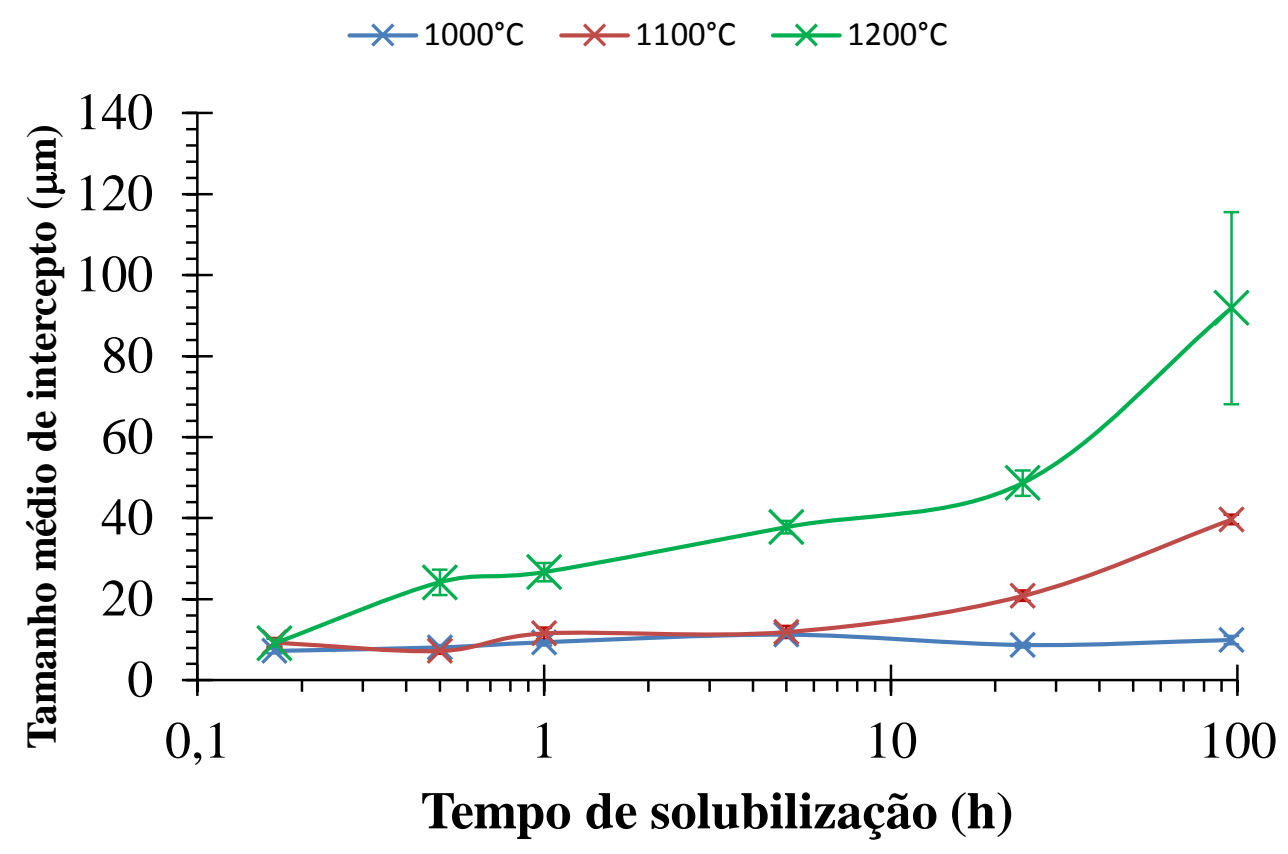

Figura 5: Tamanho de grão vs. tempo de solubilização, para as três temperaturas de tratamento: 1000,1100 e $1200^{\circ} \mathrm{C}$.

Ao fazer uma avaliação das microestruturas da Figuras 2 a 4 e dos comportamentos destacados na Figura 5, percebe-se que para todas as temperaturas de tratamento, o tamanho de grão inicial ficou em torno de um valor muito próximo a $9 \mu \mathrm{m}$. A partir do tempo de 5 horas, houve um aumento do grão da amostra tratada a $1100^{\circ} \mathrm{C}$, para os tempos de $24 \mathrm{~h}$ (próximo de $20 \mu \mathrm{m}$ ) e 96 horas (próximo de $40 \mu \mathrm{m}$ ). Não obstante, para o tratamento a $1200^{\circ} \mathrm{C}$, a diferença no tamanho de grão passou a ser evidente a partir do período de 30 minutos, onde o grão atingiu os $20 \mu \mathrm{m}$. Nos tempos subsequentes, o grão foi crescendo gradualmente até chegar a um tamanho de $100 \mu \mathrm{m}$ com 96 horas no forno. Logo, fica claro que o aumento da temperatura de

* Contribuição técnica ao 69 Congresso Anual da ABM - Internacional e ao 14ํㅡㄹ ENEMET - Encontro Nacional de Estudantes de Engenharia Metalúrgica, de Materiais e de Minas, 21 a 25 de julho de 2014, São Paulo, SP, Brasil. 


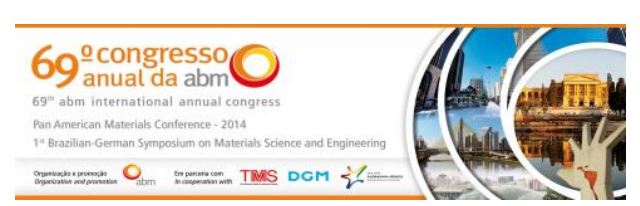

tratamento tem um efeito mais pronunciado no tamanho de grão do que o aumento do tempo de solubilização.

Para a quantificação de ferrita por esteorologia quantitativa, o contraste (ferrita preta; austenita branca) entre as fases foi conseguido pelo ataque químico Beraha modificado. As micrografias (Figura 6), da esquerda para a direita, são da menor para a maior temperatura de solubilização pelo tempo de 5 horas.

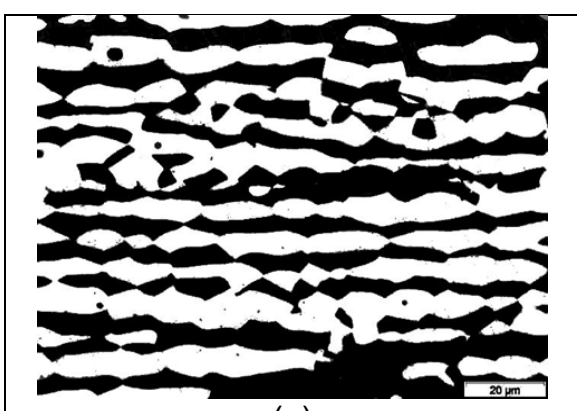

(a)

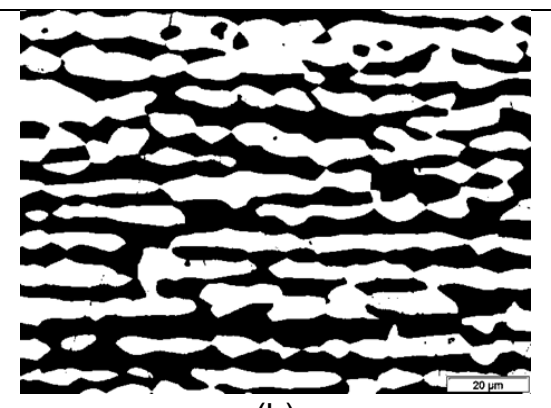

(b)

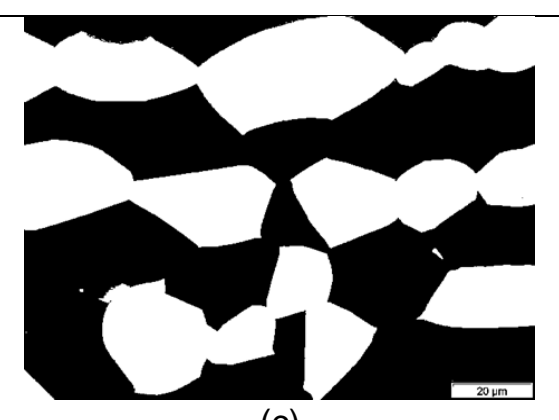

(c)

Figura 6: Micrografias ilustrando a microestrutura dúplex solubilizada por $5 \mathrm{~h}$, em que a região branca é a fase austenita e a região preta é a fase ferrita. a) $1000^{\circ} \mathrm{C}$; b) $1100^{\circ} \mathrm{C}$; c) $1200^{\circ} \mathrm{C}$. Ataque: Beraha modificado; Aumento: 1000x.

Os resultados, para a fração de ferrita das amostras solubilizadas a $1000^{\circ} \mathrm{C}$, podem ser visualizados na Figura 7, em que estão os gráficos construídos tanto por dados obtidos pelo ferritoscópio (Figura 7a) e por esteorologia quantitativa (Figura 7b). Além disso, foi feita uma comparação dos resultados obtidos pelas duas técnicas com os valores fornecidos pelo software Thermo-Calc (linha vermelha nos gráficos das Figuras 7a e 7b).

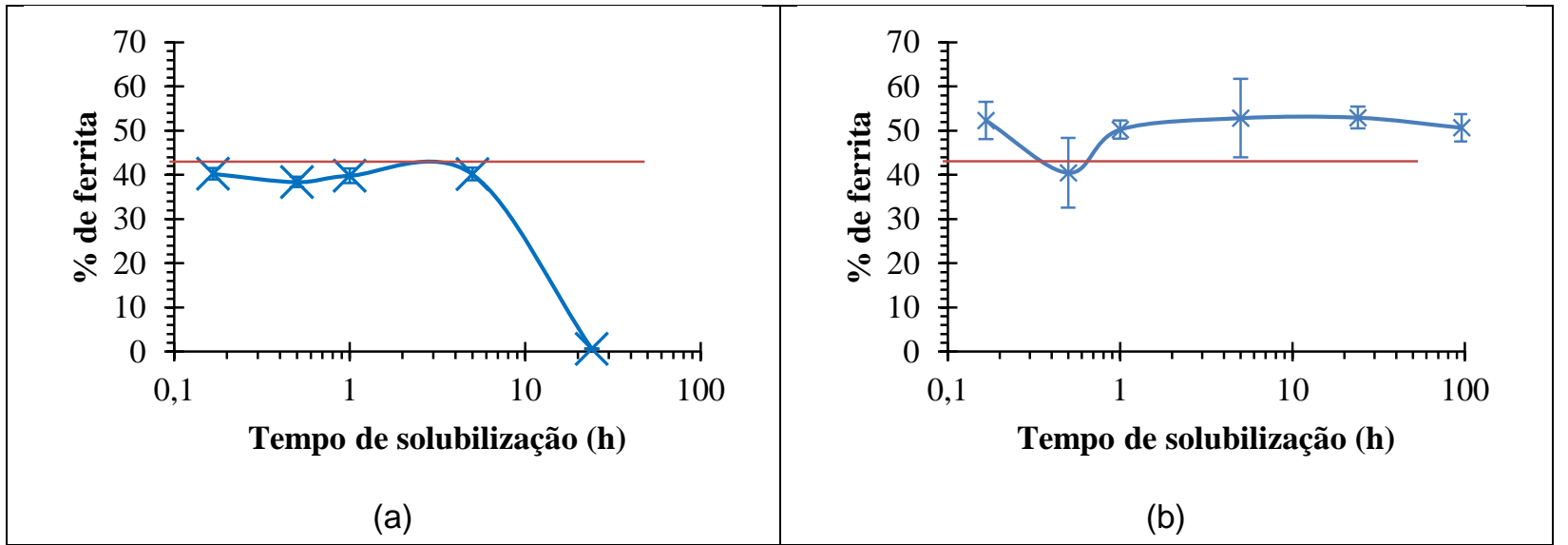

Figura 7: Quantificação da fração de ferrita da amostra tratada a $1000^{\circ} \mathrm{C}$. a) Ferritoscópio; b) Esteorologia quantitativa. A linha vermelha representa a fração de ferrita calculada no software Thermo-Calc.

Pelo gráfico de ferritoscópio, percebe-se que o valor médio para a fração de ferrita ficou em torno de $40 \%$. Já por esteorologia quantitativa, a fração de ferrita ficou em torno de $50 \%$. No equilíbrio, a fração de ferrita, pelo diagrama obtido no ThermoCalc, é de aproximadamente $43 \%$. A partir desses resultados, as duas técnicas utilizadas tiveram boa acurácia, sendo o valor mais próximo ao equilíbrio obtido pelo ferritoscópio. Além disso, para as amostras a $1000^{\circ} \mathrm{C}$, a esteorologia quantitativa foi mais confiável, já que detectou ferrita a 24 e 96 horas, enquanto o ferritoscópio não

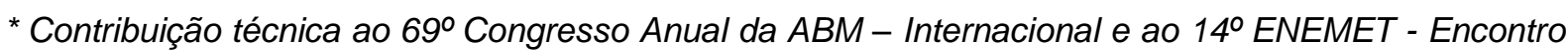
Nacional de Estudantes de Engenharia Metalúrgica, de Materiais e de Minas, 21 a 25 de julho de 2014, São Paulo, SP, Brasil.
} 


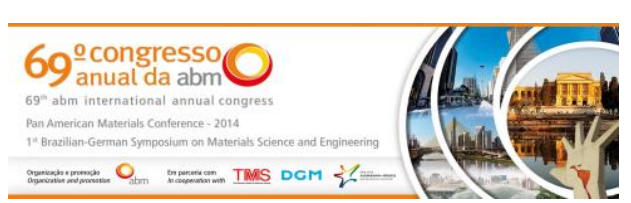

conseguiu a detecção desta fase, provavelmente por problemas de textura das amostras.

Para as amostras solubilizadas a $1100^{\circ} \mathrm{C}$, os resultados obtidos estão descritos na Figura 8. As frações de ferrita obtidas por ferritoscópio e por esteorologia quantitativa foram de aproximadamente $40 \%$ e $60 \%$, respectivamente. A fração de ferrita no equilíbrio calculado por Thermo-Calc (linha azul nos gráficos das Figuras $8 a$ e $8 b$ ) ficou em torno de $55 \%$. Com isso, a técnica de esteorologia quantitativa mais uma vez gerou um resultado mais próximo do equilíbrio.

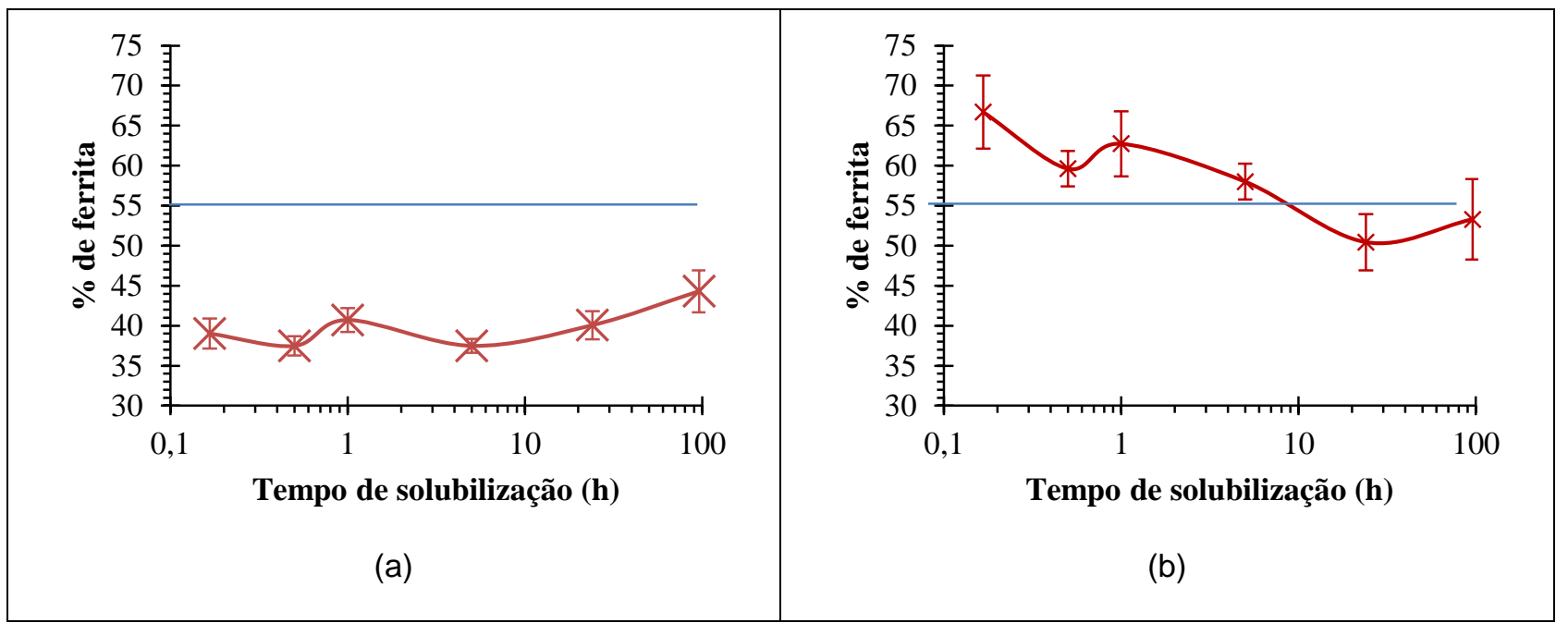

Figura 8: Simulação da fração volumétrica das fases presentes no aço dúplex para a temperatura de $1100^{\circ} \mathrm{C}$. a) Ferritoscópio; b) Esteorologia quantitativa. A linha azul representa a fração de ferrita calculada no software Thermo-Calc.

Os resultados para as amostras tratadas a $1200^{\circ} \mathrm{C}$ podem ser visualizados na Figura 9. Pelos gráficos obtidos, nota-se que a fração média de ferrita registrada pelo ferritoscópio foi de $50 \%$, enquanto que a fração média calculada por esteorologia quantitativa foi de $60 \%$. É possível perceber também que, da mesma forma que nas temperaturas anteriormente informadas, a técnica que ficou mais próxima ao valor de ferrita no equilíbrio calculado pelo Thermo-Calc, que é de $70 \%$ (linha azul nos gráficos das Figuras 9a e 9b), foi a esteorologia quantitativa. As curvas de ambas as técnicas apresentaram comportamento bem similar, até o fato inesperado de queda da fração de ferrita para os tempos de 24 e 96 horas, provavelmente relacionada à textura de recristalização gerada pelo excessivo tamanho de grão das amostras, que pode ter influenciado nas medições magnéticas do ferritoscópio.

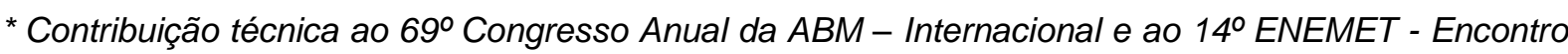
Nacional de Estudantes de Engenharia Metalúrgica, de Materiais e de Minas, 21 a 25 de julho de 2014, São Paulo, SP, Brasil.
} 


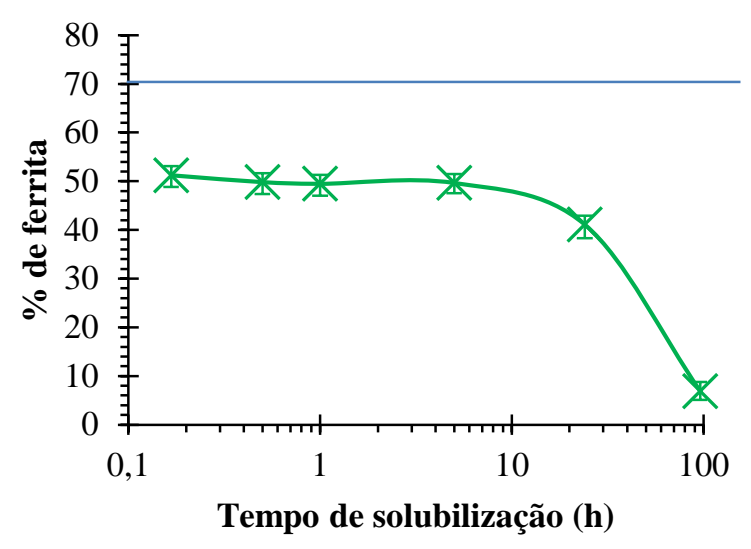

(a)

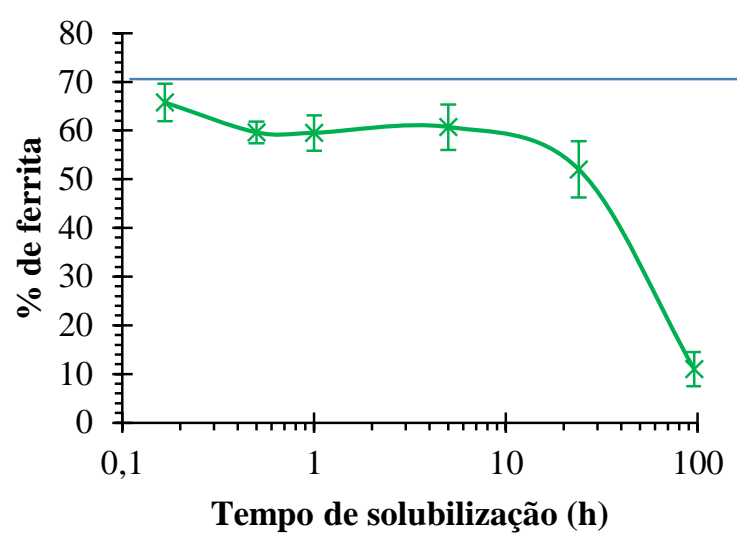

(b)

Figura 9: Quantificação da fração de ferrita da amostra tratada a $1200^{\circ} \mathrm{C}$. a) Ferritoscópio; b) Esteorologia quantitativa. A linha azul representa a fração de ferrita calculada no software ThermoCalc.

\section{CONCLUSÕES}

$\checkmark$ Todos os tratamentos de solubilização realizados a 1000,1100 e $1200^{\circ} \mathrm{C}$ propiciaram a reorganização da microestrutura deformada plasticamente, através dos fenômenos de recuperação, recristalização e crescimento de grão.

$\checkmark$ O tamanho de grão médio de ferrita e austenita, analisados indistintamente, para as amostras solubilizadas a $1000^{\circ} \mathrm{C}$ teve pequeno aumento e mantevese praticamente constante, levando-se em conta os tempos de solubilização estudados.

$\checkmark$ As amostras solubilizadas a $1100^{\circ} \mathrm{C}$ tiveram um crescimento de grão significativo a partir do tempo de 5 horas de tratamento, e no tratamento a $1200^{\circ} \mathrm{C}$, maior temperatura de solubilização estudada, constatou-se significativo crescimento de grão nas amostras a partir de 30 minutos de tratamento.

$\checkmark$ A influência da temperatura de solubilização no tamanho de grão e na fração de ferrita foi mais significativa que a exercida pelo tempo de tratamento.

$\checkmark$ A fração de ferrita aumentou com o aumento da temperatura de solubilização.

$\checkmark$ A técnica de esteorologia quantitativa utilizada para a medição da fração de ferrita teve boa acurácia, visto que os resultados foram compatíveis com as simulações de equilíbrio em Thermo-Calc.

\section{REFERÊNCIAS}

1 Hochmann J. et al. Stress Corrosion Cracking and Hydrogen Embrittlement of Iron Base Alloys, NACE-5, pp. 956, 1977.

2 Eckenrod JJ, Pinnow KE. Effects of chemical composition and thermal history on the properties of alloy 2205 duplex stainless steel. In: New developments in stainless steel technology. Detroit 1984 p.77-87.

3 Sedriks AJ. Corrosion of stainless steels. John Wiley : NY 1996 2. ed. p. 1-4.

4 Callister WD. Ciência e engenharia de materiais: uma introdução. 7 ed. Rio de Janeiro: LTC, 2008.

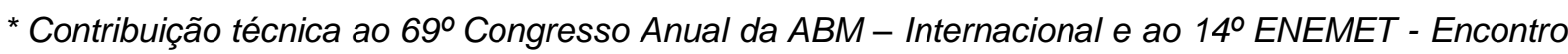
Nacional de Estudantes de Engenharia Metalúrgica, de Materiais e de Minas, 21 a 25 de julho de 2014, São Paulo, SP, Brasil.
} 
5 Agarwal DC. Duplex stainless steels - The cost effective answer to corrosion problems of major industries. Key Eng. Mater., 1988; 20-28(2): 1677-92.

6 Schillmoller CM, Klein HP. Selecting and using some high technology stainless steels. Metal Progress fev. 1981 p. 22-9.

7 Solomon HD, Devine Jr. TM. Duplex stainless steels - a tale of two phases. In: Duplex stainless steels - conference proceedings. ASM Metals Park: Ohio 1982 p. 693-756.

8 ASTM E 112-13, "Standard test methods for determining average grain size", ASTM American Society for Testing and Materials, Philadelphia, USA, 2013, Committee E-4, pp. 1-23.

* Contribuição técnica ao $69^{\circ}$ Congresso Anual da ABM - Internacional e ao 14ํㅡㄹ ENEMET - Encontro Nacional de Estudantes de Engenharia Metalúrgica, de Materiais e de Minas, 21 a 25 de julho de 2014, São Paulo, SP, Brasil. 